\title{
Low educational status restrains mental resources management in
}

\section{dual tasks}

\section{Mariane A. Machado ${ }^{1}$, Mariana C. Voos ${ }^{1,2}$, Patrícia S. Teixeira ${ }^{1}$, Maria E. Piemonte $^{1}$ \& Luiz Eduardo R. do Valle ${ }^{2}$}

\author{
${ }^{1}$ Department of Physical Therapy, Speech Therapy and Occupational Therapy, Faculty of \\ Medicine, University of São Paulo, São Paulo, \\ SP, Brasil 05360-160 \\ 2 Department of Physiology, Institute of Biomedical Sciences, University of São `Paulo, São Paulo, \\ SP, Brasil 05360-160
}

\section{Low educational status restrains mental resources management in dual tasks}

\begin{abstract}
Some studies have reported the influence of educational status on visual and motor tasks. The aim of this study was to compare the performance of adults with low (2.3 \pm 1.9 years of formal education) and high educational status $(16.1 \pm 4.0$ years) in a dual-task, composed of a visual and a motor task performed simultaneously. The visual task consisted of the presentation of two pictures that had to be verbally classified as equal or different. The motor task consisted of alternating steps from the floor to a stool. The tasks were assessed individually (simple-task) and associated (dual-task), and the performance in each condition was compared by ANOVAs. The low educational status group (LESG) committed more errors in the visual stimuli classification and performed a lower number of alternations of steps per second when compared to the high educational status group (HESG). During the dual-task performance, visual task errors increased and the number of alternations of steps per second decreased for both groups, in comparison with the single-task. However, the LESG was less accurate at classifying the stimuli during the dual-task condition than the HESG. Our findings suggest that having only a few years of formal education might decrease the ability to manage mental resources in dual-tasks.
\end{abstract}

Key Words: Tasks performance and analysis, attention, motor activity, educational status, visual perception.

\section{Introduction}

Activities of daily living require the ability to attend to concurrent tasks. Although we are constantly trying to learn how to perform dualtasks, our capability to perform tasks in parallel is limited. The literature describes forms of negative interference between concurrent tasks (Brown \& Bennett, 2002; Hazeltine, Ruthruff \& Remington, 2006). This interference usually occurs when two or more tasks are associated with one another because they may be performed with less speed and less accuracy than when they are performed separately (Eversheim \& Bock, 2001; Heralth, Torkel, Jeremy, Kathrin \& Per, 2001). Dual-task interference may occur if the attentional capacity limits are exceeded (Bourke, Duncan \& NimmoSmith, 1996). These limits are reduced due to aging (Bherer, Kramer, Peterson, Colcombe, Erickson \& Becic, 2005; Lacour, Bernard-Damanze \& Dumitrescu, 2008), brain damage (Brown, Sleik \&
Winder, 2002; Calvanio, Williams, Burke, Mello, Lepak \& Al-Adami, 2004), or if the task demands more attention due to a high level of difficulty (Beilock, Wierenga \& Carr, 2002; Brown \& Bennett, 2002).

Dual-task interference is observed when concurrent tasks compete for attentional resources. It can be assumed that in this situation, both tasks present superposed cortical representations (Roland $\&$ Ziles, 1998). Therefore, if a group of neurons is engaged in a task, it will not be completely available to perform a concurrent activity. Thus, the attentional resources will have to be shared between both tasks, and the performance of one or both may decrease. Another theory postulates that perceptual and motor operations can occur in parallel and a central bottleneck must prioritize one of them. When one operation is favored, the other will be delayed (Pashler, 1994). One other theory explains that if two tasks must be executed on successive stimuli, the response to the second 
stimulus can be delayed when the stimulus onset asynchrony (SOA) is short (Zalonis, Kararizou, Triantafyllou, Kapaki, Papageorgiou \& Sgouropoulos, 2008). Many studies have investigated this phenomenon, known as the "psychological refractory period" (PRP) (Bherer, Kramer, Peterson, Colcombe, Erickson \& Becic, 2005; Luria \& Meiran, 2005).

We did not find studies that investigated the impact of formal education on dual-task performance. Several studies have shown that formal education modifies cortical organization (Snowdon, Kemper, Mortimer, Greiner, Wikstein \& Markesbery, 1996). Our premise was that educational status would also interfere with dualtask performance. First, it is possible that educational level could interfere with the performance of concurrent visual and motor tasks because many studies have shown that formal education influences the results of visuospatial tests (Peterson, Reis \& Ingvar, 2001; Reis, Faísca, Ingvar \& Peterson, 2006; Shichita, Shuichi, Ohashi \& Matuzaki, 1986). For instance, formal education has a global impact on the Benton Visual Retention Test (Shichita, Shuichi, Ohashi \& Matuzaki, 1986), which requires strategic visual search of the targets for item recognition. Second, low educational status tended to have a negative impact on motor coordination tasks (Dansilio \& Charamelo, 2005; Nitrini, Caramelli, Herrera, Charcat-Fichman \& Porto, 2005; Ostwald, Snowdon, Rysavy, Keenan \& Kane, 1989). Figure copying was examined in adults with little formal education and compared to age- and sex-matched controls with a higher level of education. The individuals with lower educational status could not reproduce the perspective and structure, which would be classified as apraxic errors according to many scales in the literature (Dansilio \& Charamelo, 2005). Additionally, studies with the Roman Catholic sisters, known as the Nun Study, verified that highly educated sisters had better mobility and hand coordination and a stronger handgrip than their less educated counterparts (Ostwald, Snowdon, Rysavy, Keenan \& Kane, 1989).

Third, a low educational level tended to have a negative impact on tasks that required executive function. For instance, educational level had a considerable influence on both trails A and B of the trail making test, an executive function neuropsychological test (Zalonis, Kararizou, Triantafyllou, Kapaki, Papageorgiou \& Sgouropoulos, 2008). Fourth, education is one of the main factors involved in the formation of a cognitive reserve capacity (Leternneur, Gilleron, Commenges, Helmer, Orgogozo \& Dartigues,
1999; Snowdon, Kemper, Mortimer, Greiner, Wikstein \& Markesbery, 1996), which may delay the clinical expression of diseases (Schmand, Smit, Geerlings \& Lindeboom, 1997). Education is a major component of the reserve capacity, giving a greater capacity to highly educated subjects to use compensatory strategies to offset the cognitive repercussions of the first stages of a neurodegenerative process.

The aim of this study was to examine whether a group composed of individuals with a low educational status (LESG) differ from another with a high educational status (HESG) in a visual and a motor task performed individually and in conjunction with one another. Previous studies showed that individuals with few years of education presented poorer performance in visual perception tasks (Peterson, Reis \& Ingvar, 2001; Reis, Faísca, Ingvar \& Peterson, 2006). For this reason, it was possible that in the visual task, which was moderately difficult, the LESG would commit a higher number of errors than the HESG both in the single-task and in the dual-task conditions. In the motor task, which was relatively simple, we did not expect any difference between the groups when the task was isolated, since in other studies this difference was found only in complex motor tasks (Dansilio \& Charamelo, 2005; Nitrini, Caramelli, Herrera, Charcat-Fichman \& Porto, 2005; Ostwald, Snowdon, Rysavy, Keenan \& Kane, 1989). Finally, we expected that the LESG would experience a higher difficulty performing the dual-task compared to the HESG because in this condition a higher participation of executive function is needed (Allali, Assal, Kressig, Dubost, Hermann \& Beauchet, 2008).

\section{Methods}

\section{Participants}

Twenty-four subjects (25-55 yrs), who volunteered to take part in this study after seeing invitation banners in the university campus, participated in the experiment: 12 adults $(7 \mathrm{M}, 5 \mathrm{~F}$, $37.1 \pm 10.6$ yrs, BMI 22.23 \pm 1.32 ), with more than ten years of formal education (16.2 $\pm 4.1 \mathrm{yrs})$ (HESG), paired with 12 adults (6 M, 6 F, 39.9 10.4 yrs, BMI 22.34 \pm 1.58 ), with one to five years of formal education $(2.3 \pm 1.9 \mathrm{yrs})$ (LESG). All were healthy and right-handed, did not have the habit of playing videogames (by self-report), and had normal or corrected-to-normal vision (measured by the Snellen and Amsler charts). None of them had cognitive impairment, as measured by the Brazilian version of the Mini Mental State Examination 
(Brucki, Nitrini, Caramelli, Bertolucci \& Okamoto, 2003). The protocol was approved by the Local Ethics Committee, and informed consent was obtained from each subject before participation in the study. The experiment was run in a room with acoustical isolation and reduced illumination.

\section{Familiarization task}

Before the experiment, a familiarization block with ten trials of the visual task, followed by fifteen seconds of the motor task was run to assure the correct understanding of the task. The results of this block were not recorded.

\section{Visual task}

Each subject performed the visual task standing and facing a fifteen inch monitor located $70 \mathrm{~cm}$ in front of the subject at eye level. A computer with the MEL2 application (Psychology Software Tools, Inc., Pittsburgh, PA) and a joystick were used to provide the stimuli and allow the examiner to register the verbal answers of the visual task. The task was based on part 2 of the Useful Field of View (Posit Science, San Francisco, CA) (Pashler, 1994). It consisted of recognizing two targets presented simultaneously for $150 \mathrm{~ms}$, one at the center of the monitor and the other on its periphery. The screen background was gray. In the periphery, $15 \mathrm{~cm}$ from the center of the screen, there were eight white rectangles $\left(20 \mathrm{~cd} / \mathrm{m}^{2}\right.$ bright, $3 \mathrm{~cm}$ tall, 4 $\mathrm{cm}$ wide, $0.2 \mathrm{~cm}$ thick).

Each trial began when a white cross appeared in the center of the screen. After $1750 \mathrm{~ms}$, two targets appeared, one at the center (on the cross) and the other inside one of the rectangles in the periphery. These targets could either be the figure of a truck $\left(20 \mathrm{~cd} / \mathrm{m}^{2}\right.$ bright, $2 \mathrm{~cm}$ tall $\mathrm{X} 3 \mathrm{~cm}$ wide) or a bus $\left(20 \mathrm{~cd} / \mathrm{m}^{2}\right.$ bright, $2 \mathrm{~cm}$ tall $\mathrm{X} 3 \mathrm{~cm}$ wide). The targets were displayed in one of the following possible locations: bus at the center and bus at the periphery, bus at the center and truck at the periphery, truck at the center and truck at the periphery and truck at the center and bus at the periphery. The peripheral target could appear randomly in any of the rectangles. Participants were instructed to look at the cross during the experiment. After the targets had disappeared, there was a pause of $10 \mathrm{~s}$ in which participants had to say if the targets had been equal or different. An examiner, who could not see the screen, registered the answers given by the participant by pressing the left (equal) or the right (different) button of a joystick. The words "equal" and "different were written on each button. A beep was heard by the participant for each correct answer. When no answer was given within $10 \mathrm{~s}$, it was considered wrong.

Each visual task block consisted of 32 trials (see experimental design for further information). The time needed by the volunteer to finish the 32 trials was recorded and used in the motor task (if the volunteer finished the visual task after 2 minutes and five seconds, he/she was asked to alternate steps for 2 minutes and five seconds during the following motor task).

\section{Motor task}

The motor task consisted of alternating right and left steps, as fast as possible, on a $10-\mathrm{cm}$ stool, with non-slippery surface, fixed to the floor, without looking at the feet. This task had the same duration as the visual task. The movements were filmed and counted by an examiner after the end of the experiment.

\section{Experimental design}

The experiment had eight blocks: (1) familiarization; (2) visual task; (3) motor task; (4) visual task; (5) motor task; (6) dual-task (visual and motor tasks simultaneously); (7) visual task; and (8) motor task. The tasks were performed in isolation twice before moving on to the dual-task. The tasks were also performed in isolation after the dual-task to verify if motor and attentional exhaustion had interfered with the experiment in the dual-task condition. If a decrease in performance was seen in (6) but not in (7) and (8), the interference between the tasks would be the most likely explanation. If there was a decrease in performance in (6) but also in (7) and/or (8), we could conclude that fatigue contributed to the loss of performance.

To test the hypothesis that there is mutual negative interference between the two tasks when performed together, the number of steps per second in the absence and in the presence of the visual task and the number of errors in the visual task in the absence and in the presence of the motor task were compared by two-way ANOVAs ( 2 groups $\mathrm{x} 4$ blocks, for each task). The factor block was treated as repeated measures. The variables analyzed in the motor task were the mean alternations of steps per second under single-task (M1, M2, M4) and dualtask conditions (M3). The variables analyzed in the visual task were the mean number of errors in the visual task under single-task (V1, V2, V4) and dual-task conditions (V3). 


\section{Results}

Visual task

ANOVA revealed an effect of group $(\mathrm{F}(1,22)=7.27, \mathrm{p}=0.013)$, block $(\mathrm{F}(3,66)=23.50$, $\mathrm{p}<0.001)$ and an interaction between the group education level and the visual task block $(\mathrm{F}(3,66)=4.71, \mathrm{p}=0.004)$ (fig. 1).

Analysis by the post-hoc Tukey test showed that the HESG committed a lower number of errors in the second, third and fourth executions of the visual task (V2, V3 and V4) compared to its first execution (V1) $(\mathrm{p}=0.029, \mathrm{p}<0.001$ and $\mathrm{p}<0.001$, respectively). The number of errors in V4 was also lower than in V2 for this group $(p=0.019)$.

The post-hoc Tukey test also showed that the LESG committed a lower number of errors in the second and fourth executions of the visual task (V2 and V4) compared to its first execution (V1) ( $p=0.029$ and $p=0.002$, respectively).

The LESG committed more errors than the HESG during the dual-task (V3) $(\mathrm{p}=0.016)$ and during the single-task (V4) $(\mathrm{p}=0.050)$.

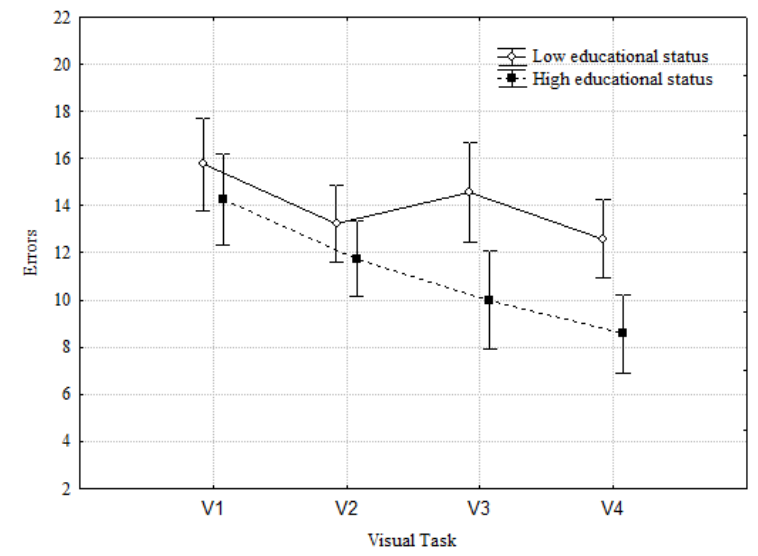

Figure 1: Mean number of errors in the visual task under single-task (V1, V2, V4) and dual-task conditions (V3).

\section{Motor task}

In the motor task, the LESG had a poorer motor performance than the HESG $(F(1,22)=6.400$, $\mathrm{p}=0.019)$. The groups varied in performance during the blocks $(\mathrm{F}(3,66)=23.997, \mathrm{p}<0.001)$.

The post-hoc Tukey test showed that the second (M2), third (M3) and fourth (M4) executions of the task were faster than the first (M1) $(\mathrm{p}<0.001$, $\mathrm{p}=0.004$ and $\mathrm{p}<0.001$, respectively) for both groups. When the motor task (M3) was associated with the visual task, both groups presented a reduction in the number of alternations per second in relation to the previous $(\mathrm{M} 2)(\mathrm{p}=0.017)$ and subsequent (M4) $(\mathrm{p}<0.001)$ executions of the motor task individually. There was no interaction between the group education level and the motor task block $(\mathrm{F}(3,66)=0.600, \mathrm{p}=0.617)$ (fig. 2).

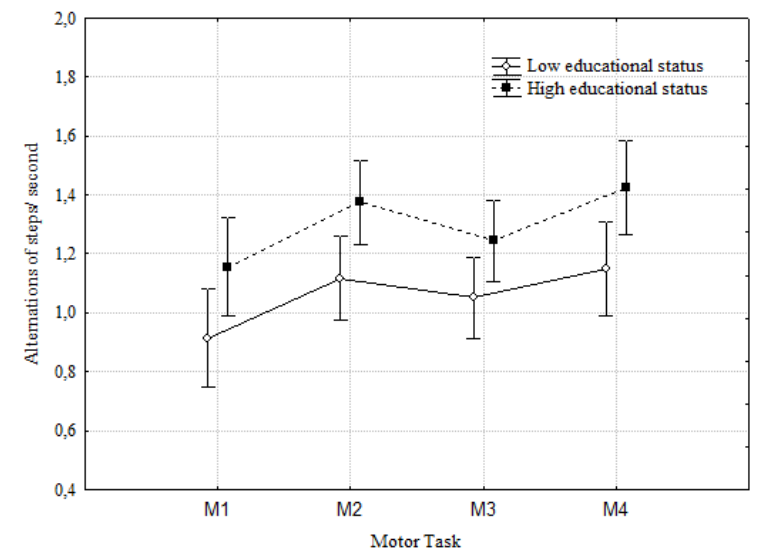

Figure 2: Mean alternations of steps per second in the motor task under single-task (M1, M2, M4) and dual-task conditions (M3).

\section{Discussion}

The present study investigated the influence of educational status on the performance of a visual and a motor task performed individually and concurrently. In terms of the visual task performed alone, our premise was that the LESG would have a poorer performance compared to the HESG. The LESG did, in fact, commit a higher number of errors in V3 (dual-task) and V4 (single-task) than the HESG, but not in V1 and V2 (single-task). We believe that, in the first presentations (V1 and V2) the visual task was very hard for all participants, however, the HESG, but not the LESG, improved its performance with training.

Previous studies reported that individuals with low educational status had difficulty recognizing geometrical shapes and two-dimensional figures (Peterson, Reis, Ingvar, 2001; Reis, Faísca, Ingvar, Peterson, 2006). Subjects who have received little formal education lack orthographic knowledge, which facilitates the analysis and decodification of 2-D information (Reis, Faísca, Ingvar, Peterson, 2006). The low level of education implies that these subjects did not have the opportunity to systematically learn and practice processing conventional 2-D information, what may explain why the HESG improved its performance, but the HESG did not.

Although both groups started the visual task with a high number of errors, near $50 \%$ in V1 (fig 2 ), the two groups presented distinct behaviors in the visual task when it was performed with the motor task (dual-task) (V3) and, more interestingly, this distinction, which had not been seen in the first 
and second blocks, remained in the subsequent block (V4), when the visual task was performed in isolation. Therefore, the addition of the motor task was detrimental to the performance of the LESG, not only during the dual-task (V3), but also after that (V4). In the HESG, the addition of the motor task did not impair performance and did not impede its improvement. Some studies suggest that the training diminishes the negative interference between tasks performed simultaneously (Melzer \& Oddsson, 2004; Spelke, Hirst \& Meisser, 1976), but the interesting fact is that this only happened in the HESG. Thus, both groups showed learning effects during the repetition of the visual task, but the practice did not have the same effect for the two groups. These findings suggest that during the performance of a visual task, individuals with little education are more susceptible to interferences than the individuals with a high educational status.

Some studies have reported an improvement in the performance of cognitive tasks when they were associated with auditory information (Jamet, Deviterne, Gauchard, Vançon \& Perrin, 2006; Sparrow, Bradshaw, Lamoureux \& Tirosh, 2002). This suggests that the auditory feedback (beep) for each correct answer could have helped during the visual task because it indicated that the strategy adopted by the individual to classify the stimuli was correct, providing positive reinforcement. However, as the subjects with lower educational level tend to be more conservative when they choose their strategies, due to their lower cognitive flexibility (Nitrini, Caramelli, Herrera, CharcatFichman \& Porto, 2005), there is a chance that the beep did not provide the same benefit for them. Another possibility is that the auditory feedback could have contributed to increased anxiety during the test, since its absence meant error. The LESG committed more errors and may have felt more anxious as a consequence. On the other hand, this group was less familiar with the situation of being tested because these participants had not been to school for many years, which also could have contributed to anxiety and errors (Ardila, 2000).

It is important to consider that a higher difficulty in processing linguistic elements could have contributed to the inferior performance of the LESG. Studies have shown that individuals with lower educational status possess a lower comprehension of verbal information (Nitrini, Caramelli, Herrera, Charcat-Fichman \& Porto, 2005). The differences could also be partially explained by the distinct general learning opportunities that both groups had throughout their lives (Ardila, 2000).
It is important to emphasize that not only the formal education, but also the experiences related to it, such as the social and economical level of the individual and the stimulation provided during childhood and adolescence (Ardila, 2000), may reduce cognitive efficiency and should not be neglected.

Dansilio \& Charamelo (2005) and Nitrini, Caramelli, Herrera, Charcat-Fichman \& Porto (2005) have demonstrated that individuals with a low level of education had a poorer performance of complex motor tasks than highly educated individuals. We did not expect, however, to find a difference in the performance of an isolated single motor task because we supposed it would be low in complexity. In actuality, we found that the LESG performed fewer alternations of steps than the HESG.

A possible explanation for this finding is that the LESG, due to their higher anxiety and insecurity level in testing situations (Ardila, 2000), might decrease their speed to avoid making mistakes. Although alternating steps from the floor to a $10-\mathrm{cm}$ stool in a reduced illumination room is not a difficult task for 25- to 55-year-old adults, one can stumble when the triple flexion (i.e. ankle dorsiflexion, knee and hip flexion) of the lower limb is insufficient, resulting in collision of the anterior region of the foot with the stool. This stumbling occurred a few times with some subjects of both groups.

We expected the LESG to have a more significant reduction in the number of alternations per second in the dual-task than the HESG. The fact that this predicted outcome did not occur was likely because the LESG performed the motor task at a slower speed during all the experiment. They may have performed the motor task slower than their maximum capability in order to avoid making mistakes and maintain their performance when faced with a higher cognitive demand (dual-task). Alternatively, they may have realized that they would not be able to perform the visual task properly at a higher speed of motor task performance, so they reduced the number of step alternations. It is interesting to note that although neuronal circuitries of motor control usually become more restricted and efficient when a movement is trained, cognitive resources did not seem to be available to aid in the performance after the dual-task.

Because the performance in M4 was better than in M3, and the performance of V4 was better than V3 for both groups, the reduction in speed of the motor task and the higher number of errors of the visual task during the dual-task performance did 
not occur due to fatigue but due to difficulty in processing and executing the motor task when it was associated with the visual task.

Some authors postulate that two strategies are usually implemented during the planning of a movement. The first is based on the visual analysis of the movement (sensory strategy), with the transformation of the visual inputs into motor representations. The second is based on the verbal interpretation of the movement (semantic strategy), when, for instance, a verbal command is given. Highly educated individuals use both strategies to reproduce and adjust their movements when they are asked to perform a sequence of movements (Nitrini, Caramelli, Herrera, Charcat-Fichman \& Porto, 2005). In contrast, the verbal strategy is less elaborated in individuals with a low level of education (Brucki \& Rocha, 2004; Ratcliff, Ganguli, Chandra, Sharma, Belle, Seaberg \& Pandav, 1998), which makes them almost completely dependent on the visual strategy, resulting in increased failure and lower scores in many motor tests.

Another interesting finding is that the groups differed in their acquisition of the tasks. When the visual task was performed in conjunction with the motor task, the HESG kept improving their visual task performance, but showed impairment in the motor task performance. The LESG committed more errors in the visual task, but did not present a higher disruption of the motor task in comparison to the HESG. It is possible that the visual task was neglected by the LESG in favor of the motor task because the visual task was more complex and demanded more attention.

As limitations of the study, we must mention that the groups had a different number of males and females, what could have influenced our results. However, our pilot studies and a study with a similar task showed no gender differences. Cowan and Crossley (2009), evaluated differences in the neuromotor control of the knee and hip muscles between genders, using a visual choice reactiontime stair stepping task. They found significant associations between EMG measures of motor control of the vasti and hip strength in both females and males, but no significant difference between genders.

Also, we must state that the number of errors in the visual task was close to $50 \%$, mainly in V1, what shows that the visual task may have been very difficult for all participants. However, although the HESG managed to improve its performance, the HESG kept a very high number of errors. This shows that, even if it was very difficult, the visual task was adequate for this experimental procedure.
In conclusion, individuals with a low educational status had, in general, worse motor performance than individuals with a higher level of education. In addition, individuals with a low educational status decreased their performance in a visual task, when it was associated to a motor task.

\section{References}

Allali G., Assal F., Kressig R.W., Dubost V., Herrmann F.R. \& Beauchet O. (2008). Impact of impaired executive function on gait stability. Dement. Geriatr. Cogn. Disord. 26, 364-369.

Ardila A. (2000). Evaluación cognociva en analfabetos. Rev. Neurol. 30, 465-468.

Beilock S.L., Wierenga S.A., Carr T.H. (2002). Expertise, attention, and memory in sensorimotor skill execution: impact of novel task constraints on dual-task performance and episodic memory, Q. J. Exp. Psychol. A. 55, 1211-1240.

Bherer L., Kramer A.F., Peterson M.S., Colcombe S., Erickson K., Becic E. (2005). Training effects on dual-task performance: are there age related differences in plasticity of attentional control? Psychol. Aging 20, 695-709.

Bourke P.A., Duncan J., Nimmo-Smith I. (1996). A general factor involved in dual task performance decrement, Q. J. Exp. Psychol. 49A, 525-545.

Brown L.A., Sleik R.J., Winder T.R. (2002). Attentional demands for postural control, Arch. Phys. Med. Rehabil. 83, 1732-1735.

Brown S.W., Bennett E.D. (2002). The role of practice and automaticity in temporal and nontemporal dual-task performance, Psychol. Res. 66, 80-89.

Brucki S.M.D., Nitrini R., Caramelli P., Bertolucci P.H.F., Okamoto I.H. (2003). Sugestões para o uso do Mini-Exame do Estado Mental no Brasil, Arq. Neuropsiquiatr. 61, 777-781.

Brucki S.M.D., Rocha M.S.G. (2004). Category Fluency test: effects of age, gender and education on total scores clustering and switching in Brazilian Portuguese-speaking subjects, Braz. J. Med. Biol. Res. 37, 1771-1777.

Calvanio R., Williams R., Burke D.T., Mello J., Lepak P., Al-Adawi S. et al. (2004). Acquired brain injury, visual attention and the useful visual field of view test: a pilot study, Arch. Phys. Med. Rehabil. 85, 474-478.

Cowan S.M., Crossley K.M. (2009). Does gender influence neuromotor control of the knee and hip? J Electromyogr Kinesiol. 19, 276-82.

Dansilio S., Charamelo A. (2005). Constructional functions and figure copying in illiterates or 
low-schooled Hispanics, Arch. Clin. Neuropsychol. 20, 1105-1112.

Eversheim U., Bock O. (2001). Evidence for processing stages in skill acquisition: a dual-task study, Learn. Mem. 8, 183-189.

Hazeltine E., Ruthruff E., Remington R.W. (2006). The role of input and output modality pairings in dual-task performance: evidence for contentdependent central interference, Cogn. Psychol. 52, 291-345.

Heralth P., Torkel K., Jeremy Y., Kathrin A., Per R. (2001). Neural correlates of dual task interference can be dissociated from those of divided attention: an fMRI study, Cereb. Cortex 11, 796-805.

Jamet M., Deviterne D., Gauchard G.C., Vançon G., Perrin P.P. (2006). Age-related part taken by attentional cognitive process in standing postural control in a dual-task context, Gait \& Posture 25, 179-184.

Lacour M., Bernard-Demanze L., Dumitrescu M. (2008) Posture control, aging, and attention resources: models and posture-analysis methods, Neurophysiol. Clin. 38, 411-421.

Letenneur L., Gilleron V., Commenges D., Helmer C., Orgogozo J.M., Dartigues J.F. (1999). Are sex and educational level independent predictors of dementia and Alzheimer's disease? Incidence data from the PAQUID project, J. Neurol. Neurosurg. Psychiatry 66, 177-183.

Luria R., Meiran N. (2005). Increased control demand results in serial processing. Evidence from dual-task performance, Psychol. Sci. 16, 833-840.

Melzer I., Oddsson L.I.E. (2004). The effect of a cognitive task on voluntary step execution in healthy elderly and young individuals, J. Am. Geriatr. Soc. 52, 1255-1262.

Nitrini R., Caramelli P., Herrera E., CharcatFichman H., Porto C.S. (2005). Performance in Luria's first-edge-palm test according to educational level, Cog. Behav. Neurol. 18, 211214.

Owsley C. (1994). Vision and driving in the elderly, Optom. Vis. Sci. 71(1994) 727-735.

Pashler H. (1994). Dual-task interference in simple tasks: Data and theory, Psychol. Bull. 116, 220244.

Petersson K.M., Reis A., Ingvar M. (2001). Cognitive processing in the literate and illiterate subjects: A review of some recent behavioral and functional neuroimaging data, Scand. J. Psychol. 42, 251-267.

Ratcliff G., Ganguli M., Chandra V., Sharma S., Belle S., Seaberg E., Pandav R. (1998). Effects of literacy and education on measures of word fluency, Brain Lang. 61, 115-122.

Reis A., Faísca L., Ingvar M., Petersson K.M. (2006). Color makes a difference: twodimensional object naming in literate and illiterate subjects, Brain Cogn. 60, 49-54.

Roland P.E., Ziles K. (1998). Structural divisions and functional fields in the human cerebral cortex, Brain Res. Rev. 26, 87-105.

Schmand B., Smit J.H., Geerlings M.I., Lindeboom J. (1997). The effects of intelligence and education on the development of dementia. A test of the brain reserve hypothesis, Psychol. Med. 27, 1337-1344.

Shichita K., Shuichi H., Ohashi Y., Matuzaki T.(1986). Memory changes in the Benton visual retention test between ages 70 and $75, J$. Gerontol. 41, 385-386.

Ostwald S.K., Snowdon D.A., Rysavy S.D.M., Keenan N.L., Kane R.L. (1989). Manual dexterity as a correlate of dependency in the elderly, J. Am. Geriatr. Soc. 7, 963-969.

Snowdon D.A., Kemper S.J., Mortimer J.A., Greiner L.H., Wekstein D.R., Markesbery W.R. (1996). Linguistic ability in early life and cognitive function and Alzheimer's disease in later life, J. Am. Med. Assoc. 275, 528-532.

Sparrow W.A., Bradshaw E.J., Lamoureux E., Tirosh O. (2002). Aging effects on attention demands of walking, Human Mov. Sci. 21, 961972.

Spelke E., Hirst W., Neisser U. (1976). Skills of divided attention, Cognition 4, 215-230.

Zalonis I., Kararizou E., Triantafyllou N.I., Kapaki E., Papageorgiou S., Sgouropoulos P. et al. (2008). A normative study of the trail making test A and B in Greek adults. Clin. Neuropsychol. 22, 842-850.

\section{Endereço para correspondência:}

Callil Voos.

Departamento de Fisioterapia, Fonoaudiologia e Terapia Ocupacional da Faculdade de Medicina. Universidade de São Paulo.

Rua Cipotânea, 51,

São Paulo, SP, Brasil

05360-160

marivoos@usp.br.

Submetido: 19/03/2011

Revisado: $27 / 05 / 2011$

Aceito: 06/07/2011 